intensive efforts of gamekeepers and trappers appear to have reduced the rabbit to comparative scarcity over most parts of Great Britain, a position approaching that of the end of the War of 1914-18, when wild rabbits became very scarce. On the other hand, the position of the rat is still serious, and in some 'blitzed' centres and ports with bigger food stores than usual, conditions have encouraged its increase. In an article on rat control (Lancet, 1, No. 5, 1942), Mr. Eric Hardy directs attention to the value of asbestos and three-ply wood as rat-proofing materials when many usual materials are unobtainable. White arsenic is the most useful of the poisons permitted by the law. Attention is also directed to the need for using more traps--even ten times as many traps as rats-and to using unbaited traps, and the encouragement of those predatory enemies of rats in the countryside usually destroyed by gamepreservation, namely, stoats, foxes, badgers, owls, herons, otters, buzzards and polecats. The Ministry of Food's Infestation Order 1941, which came into force in January, gives added power for compulsory control of rats and other warehouse vermin.

\section{Wood Pigeon Investigation}

The British Trust for Ornithology is organizing a winter wood pigeon investigation in the British Isles which ought to shed much light upon the habits of this serious agricultural pest. Although organized from the natural history point of view, the investigation may well provide information of considerable value in the control of this pest. Explanatory forms and recording cards for field counts and roost positions have been circulated, and the inquiry will also include the examination of crop-contents of shot birds and post-mortems upon diseased birds. The field counts will make observation upon the sizes of the local flocks at every opportunity when they perch, feed, roost or are in flight, and in addition to recording the day and place, the hour of the count will be noted. Record will also be made of their daily feeding, drinking and resting times, and the influence, if any, of fog, mist, rain and increasing daylight, and if special fields are favoured for feeding and resting. Observations will be made to see if the flocks remain intact throughout the day or break up, and if pairing takes place in flocks. The roost observations will count or estimate the number of birds using the roosts, the type of wood, the trees most favoured, the period in use, and whether it is used annually and if the size of the roosting flock is increasing or decreasing. An effort will also be made to get experienced people to weigh, measure and determine the sex of shot wood pigeons. The field counts will be returned to the Edward Grey Institute at Oxford monthly, and the rest of the winter stage of the investigation will be completed by the end of May.

\section{The Swedish Botanical Garden}

THE January issue of the Anglo-Swedish Review announces that the Bergianska Trädgärden or Bergianum, the botanical garden of Stockholm, is to mark its hundred and fiftieth anniversary this year. It was founded in 1791 by Peter Jonas Berg, a doctor of medicine and a botanist, who bequeached it to the Swedish Academy of Science. It consists of a purely scientific botanical section and a practical section, which in peace-time carries on a large exchange of seeds with most of the botanical gardens abroad. Among the latter is the botanical garden of Tokyo, which had to place considerable orders to complete its collections, part of which were destroyed in the earthquake ten years ago. The Bergianum is also in close touch with the United States, and some plants from the salt steppes of Russian Turkestan recently came from Russian botanical gardens. Most of the seeds received are of purely scientific interest, but sometimes seeds and plants of commercial value are also received. The results of experiments on the effects of the vigorous cold of the last two years on different plants will shortly be published in Acta Horti Bergiani, which contains the results of resear.h work in systematics, cytology and embryology. The celebrated collection known as "Iconotheca Botanica Bergiana" contains 10,000 photographs by most of the botanists in the world. A large room in the main building is filled with cupboards which originally belonged to Bergius and contain his collections of plants and insects. Thanks to a donation, the Bergianum will soon have a winter garden where all the flora of the Mediterranean will be grown.

\section{Public Health in India}

According to the annual report for 1940 of the Public Health Commissioner with the Government of India, there were no abnormal outbreaks of disease in that year, and the common epidemic: diseases such as malaria, smallpox and plague had been less prevalent than in 1939. The most important public health event was the third meeting of the Advisory Board of Health at Poona, where reports were made on the compulsory inoculation of pilgrims at festival centres against cholera and on the control of food adulteration. The Board recommended a plan for the provision of laboratories, including for each Province or State a central laboratory, regional laboratories for groups of districts and others for individual districts. The low incidence or complete absence of the common infectious diseases such as cholera, smallpox and plague in the prisons, of which the daily population was more than 13,000, showed the efficacious control of these infections. The report also contained a chapter on medical research, especially on nutrition, by the Indian Research Fund Association, field studies on cholera, plague and malaria, leprosy research carried out mainly at the Calcutta School of Tropical Medicine, and maternal mortality investigated at Calcutta, Bombay, Delhi and Madras. Cerebrospinal fever had oceurred in sporadic form in many provinces.

\section{Radio Receiver Design}

In the past fow years radio manufacturers in Great Britain have awakened to the fact that the export industry has been very much neglected. This is shown clearly in a paper read before the Students and Graduates Sections of the Institution of Electrical Engineers by Mr.J.H.Lemmon, on "Tropical Receiver Design" (Quart. J. Inst. Elec. Eng. of December 1941). In British colonies, the majority of radio receivers in use until about 1938 were of either American or Dutch origin. British manufacturers had sent out to India or other tropical countries receivers which differed very little from those sold in the home market, and little attention was paid to the internal parts of the receiver. Mr. Lemmon takes India as the basic country, since a fairly comprehensive 